\title{
BIOLOGICAL BEHAVIOR OF LEISHMANIA AMAZONENSIS ISOLATED FROM HUMANS WITH CUTANEOUS, MUCOSAL, OR VISCERAL LEISHMANIASIS IN BALB/C MICE
}

\author{
ROQUE P. ALMEIDA, MANOEL BARRAL-NETTO, AMELIA M. R. DE JESUS, \\ LUIS A. R. DE FREITAS, EDGAR M. CARVALHO, AND ALDINA BARRAL \\ Servico de Imunologia, Hospital Universitario Professor Edgard Santos, Universidade Federal da \\ Bahia, Bahia, Brazil; Centro de Pesquisa Goncalo Moniz-FIOCRUZ, Bahia, Brazil
}

\begin{abstract}
Leishmania amazonensis causes a wide spectrum of disease in humans. In this study, we evaluated BALB/c mice infected with five strains of $L$ amazonensis isolated from patients with either cutaneous, mucosal, or visceral leishmaniasis. Mice infected with cutaneous and mucosal isolates developed ulcerating footpad lesions with parasite-loaded macrophages and extensive tissue destruction. Skin metastases, early dissemination of parasites to the spleen, and high anti-Leishmania antibody levels were also noted. Mice infected with L amazonensis strains isolated from patients with visceral disease had a controlled infection, with small footpad lesions with mononuclear cell infiltration, few infected macrophages, and granuloma formation. They had no skin metastases, delayed dissemination of the parasite to the spleen, lower levels of $\mathrm{IgG}$ and higher levels of IgG2a against $L$. amazonensis. These findings demonstrate an unexpected resistance of $\mathrm{BALB} / \mathrm{c}$ mice to the infection with $L$ amazonensis isolated from patients with visceral leishmaniasis. This resistance seems to be due to differences in these parasites that may be related to the altered course of the disease in humans and in isogenic BALB/c mice.
\end{abstract}

Leishmania is an intracellular protozoa that infects humans and causes a wide spectrum of disease. Species such as $L$ donovani and $L$ chagasi cause visceral leishmaniasis whereas $L$ major and $L$ amazonensis are usually associated with cutaneous disease and $L$. braziliensis with mucosal disease. However, L. amazonensis has recently been isolated from patients with diverse forms of leishmaniasis, including cutaneous, mucosal, diffuse, and visceral leishmaniasis, and post-kala-azar dermal leishmaniasis. ${ }^{1-3}$ Thus, $L$. amazonensis is associated with the entire spectrum of human disease, and no differences were found in the zymodeme or serodeme patterns of strains isolated from patients with different clinical manifestations. ${ }^{1}$ Leishmania tropica, usually a causal agent of cutaneous leishmaniasis, has been isolated from the bone marrow of members of the Armed Forces that had been in the Middle East. ${ }^{4}$ It has been demonstrated that BALB/c mice are highly susceptible to $L$. amazonensis infection. The disease progresses rapidly, the parasites disseminate to lymph nodes, spleen and liver, cutaneous metastases develop, and death ensues. ${ }^{5-7}$ Biological differences among parasite strains may be evident in such a susceptible host. In the present study, isogenic BALB/c mice were infected with strains of $L$ amazonensis isolated from patients with either cutaneous, mucosal, or visceral leishmaniasis and the patterns of infection and humoral immune response were followed.

\section{MATERIALS AND METHODS}

Animals. A total of 142 male and female isogenic 10-12week-old BALB/c mice, maintained with food and water ad libitum, were used.

Parasites. Five strains of $L$ amazonensis typed by serodeme and zymodeme analysis (kindly performed by Drs. G. Grimaldi and H. Momem, Fundacao Oswaldo Cruz, Rio de Janeiro, Brazil) were used. One strain was isolated from a patient with cutaneous leishmaniasis (MHOM/BH/87/BA125 , from a 12-year-old girl with a disease history of three months); two were isolated from two patients with mucosal leishmaniasis (MHOM/BR/87/Ba-113, from a 17-year-old man with a disease history of four years and MHOM/BR/ 75/Ba-Josefa, from a 27-year-old woman with a disease history of five months); and two were isolated from two patients with visceral leishmaniasis (MHOM/BR/Ba-109, from a 34-year-old man with a disease history of five months and MHOM/BR/87/Ba-137, from a three-year-old boy with a disease history of five months). The Josefa strain was selected as a prototype because it is well characterized and causes severe disease in BALB/c mice. The others four strains (cutaneous, mucosal, and visceral) were selected without any prior knowledge of their behavior in mice. The course of the disease in the patients infected with these five strains of $L$. amazonensis was similar with the disease caused by other Leishmania species found in Brazil that are the causal agents of cutaneous and mucosal leishmaniasis ( $L$. braziliensis) and visceral leishmaniasis ( $L$. chagasi). The five strains will be designated as mucosal-1, mucosal-2, cutaneous, visceral- 1 , and visceral- 2 .

Parasite isolation and culture were performed as previously described. ${ }^{8}$ Briefly, parasites were isolated in NNN medium and frozen in liquid nitrogen. For infection, parasites were thawed and grown in liquid medium (liver infusion tryptose) supplemented with $2 \%$ heat-inactivated fetal calf serum. The parasites were passaged no more than three times before infection of the animals.

Infection. Stationary phase promastigotes were washed three times (by centrifugation at $1,800 \times g$ at $4^{\circ} \mathrm{C}$ for 10 min) and adjusted to a concentration of $5 \times 10^{6}$ promastigotes $/ 20 \mu \mathrm{l}$. Subcutaneous infection was induced in the hind left footpad with a 50- $\mu$ l Hamilton (Reno, NV) syringe and a 26-gauge needle by injecting $20 \mu l$ of the promastigote suspension.

The number of mice used for testing of each Leishmania isolate was as follows: mucosal- $1(n=31)$, mucosal- $2(n=$ 30 ), cutaneous $(n=25)$, visceral-1 $(n=26)$, and visceral$2(n=30)$.

Determination of lesion size. Sizes of the footpads were measured weekly using a dial gauge caliper (Starret, Athol, 
MA). Differences between infected and contralateral, noninfected footpad measurements are referred as lesion size in millimeters.

Visceralization of parasites. After three, eight, and 15 weeks of infection, animals were killed by ether anesthesia. Spleens and popliteal lymph nodes were obtained from five mice per parasite strain and cultured in tubes containing NNN medium (three for each spleen and two for each lymph node). The cultures were examined for the presence of Leishmania promastigotes after two and four weeks.

Histology. Infected footpads were obtained from five mice at three, eight, or 15 weeks postinfection, fixed in $10 \%$ neutral formalin, embedded in paraffin, and processed for staining with hematoxylin and eosin. ${ }^{5.7}$

Serology. After three, seven, and 10 weeks of infection, sera were obtained by puncture of the retro-orbitary plexus of all remaining animals and stored at $-20^{\circ} \mathrm{C}$. Levels of antiLeishmania IgG antibody were determined in the sera from each animal. Soluble L amazonensis promastigote antigen $\left(10 \mu \mathrm{g} / \mathrm{ml}\right.$ ) (prepared as previously described ${ }^{7}$ ) was coated on 96-well, polypropylene microtiter plates (Nunc-Intermed, Naperville, IL). ${ }^{9}$ Briefly, stationary-phase promastigotes cultivated in liver infusion tryptose medium supplemented with $5 \%$ fetal bovine serum were washed three times (centrifugation at $1,800 \times g$ for $10 \mathrm{~min}$ at $4^{\circ} \mathrm{C}$ ) in phosphate-buffered saline (PBS). Parasites were resuspended at a concentration

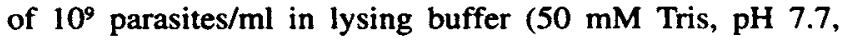
$0.12 \mathrm{M} \mathrm{NaCl}, 0.5 \% \mathrm{NP}-40,0.25 \%$ sodium deoxycholate; 0.5 $\mu \mathrm{g} / \mathrm{ml}$ of aprotinin, and $5 \mathrm{mM}$ EDTA). After incubation for $10 \mathrm{~min}$ at room temperature, the material was subjected to dialysis against 500 volumes of PBS at $4^{\circ} \mathrm{C}$, and the protein concentration was measured. ${ }^{9}$ The sera were diluted 1:100 for the measurement of anti-Leishmania IgG.

An enzyme-linked immunosorbent assay was performed with promastigote antigen. Plates were sensitized with antigen at a concentration of $10 \mu \mathrm{g} / \mathrm{ml}$ in $0.1 \mathrm{M}$ carbonate-bicarbonate buffer, pH $9.6\left(0.1 \mathrm{ml} /\right.$ well overnight at $\left.4^{\circ} \mathrm{C}\right)$. Before the reaction, the plates were washed three times with PBS containing $0.05 \%$ Tween-20 (PBS-Tween). Sera diluted 1:100 were incubated for $1 \mathrm{hr}$ at $37^{\circ} \mathrm{C}$, followed by three washings with PBS-Tween. Peroxidase-conjugated rabbitanti-mouse IgG (Sigma, St. Louis, MO) diluted 1:500 was added and incubated for $1 \mathrm{hr}$ at $37^{\circ} \mathrm{C}$. The plates were washed with PBS-Tween and substrate solution $(0.04 \% o$ phenylenediamine, $0.012 \%$ hydrogen peroxide in citratephosphate buffer, pH 5) was added. Following incubation, the reaction was stopped by adding $16 \mathrm{M}$ sulfuric acid $(0.025$ $\mathrm{ml}$ (well), and samples were read in a Titertek Multiskan spectrophotometer (Flow Laboratories, Ayrshire, Scotland) at $490 \mathrm{~nm}$.

To evaluate specific IgG1 or IgG2a, pooled sera from each group were used at a 1:10 dilution in triplicate. The reaction was revealed with the biotin-avidin peroxidase system. Biotinylated rabbit anti-mouse IgG1 and IgG2a (Amersham, Arlington Heights, IL) were diluted $1: 1,000$ and avidin-peroxidase was diluted 1:2,000. The substrate consisted of $0.04 \% o$-phenylenediamine (Sigma) and $0.012 \%$ hydrogen peroxide in phosphate-citrate buffer, $\mathrm{pH}$ 5). The IgGl and IgG2a indices were calculated to compare the contribution of these specific IgG subclasses. The index was calculated

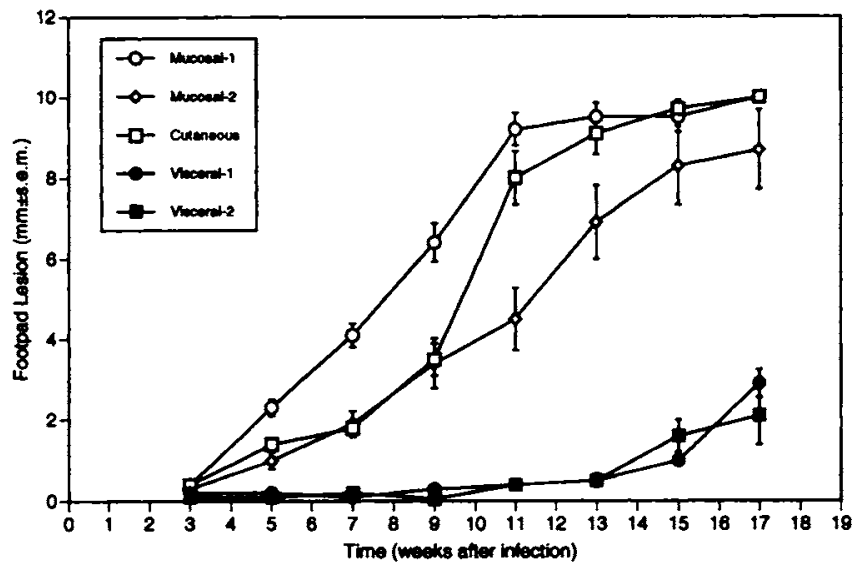

FIGURE 1. Time course of lesion development in BALB/c mice infected with $5 \times 10^{6}$ promastigotes of Leishmania amazonensis isolated from patients with cutaneous/mucosal and visceral leishmaniasis. Points represent the mean \pm SEM size (mm) of footpad lesions. The number of mice infected with each Leishmania isolate is described in the results.

as the anti-Leishmania subclass optical density (OD) divided by the total anti-Leishmania IgG OD.

Statistical analysis. Comparisons between cutaneous/mucosal groups and visceral groups were done using the MannWhitney test.

\section{RESULTS}

Course of disease. Footpad lesions from BALB/c mice infected with the cutaneous and mucosal strains of $L$ amazonensis, mucosal-1 ( $\mathrm{n}=31)$, mucosal-2 $(\mathrm{n}=30)$, and cutaneous $(n=25)$, showed progressive lesions, starting after three weeks and reaching $9 \mathrm{~mm}$ between 15 - and 17-weeks postinfection (Figure 1). Differences in lesion size among cutaneous and mucosal strains were only transiently significant (5-9-weeks postinfection), with the largest lesions in mucosal-1-infected mice. Dissemination of parasites to the tail and other footpads was observed after 15 weeks of infection (Figures $2 \mathrm{~A}$ and B). Mortality due to severe disease among animals infected with mucosal-1, mucosal-2, and cutaneous started by 15 -weeks postinfection and all had died by 25 weeks after infection.

The BALB/c mice infected with visceral strains of $L$. amazonensis, visceral-1 $(n=26)$ and visceral-2 $(n=30)$, had minimal lesions until the 13th-week postinfection $(0.5 \pm$ $0.15 \mathrm{~mm}$ [mean $\pm S E M$ ]), with slight increases thereafter. No metastases were observed in these animals even at 48weeks postinfection (Figure $2 \mathrm{C}$ ). In fact, three mice infected with visceral isolates were able to survive until the end of the study (more than 18 months) without any growing footpad lesions and metastatic lesions. Differences in lesion size between the cutaneous/mucosal groups and visceral groups were statistically significant after five weeks of infection.

The histopathologic findings in the lesions of the cutaneous/mucosal groups showed a clear predominance of heavily infected macrophages with very few lymphocytes (Figure $3 A)$. Lesions from $B A L B / c$ mice infected with the visceral strains of $L$. amazonensis showed a predominance of lymphocytes, macrophages containing few parasites, presence of plasma cells, and granulomas with giant cells (Figure 3B). 


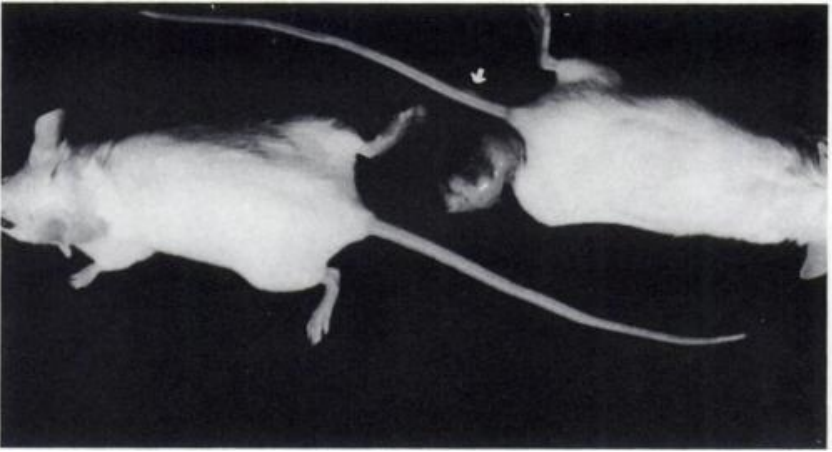

A

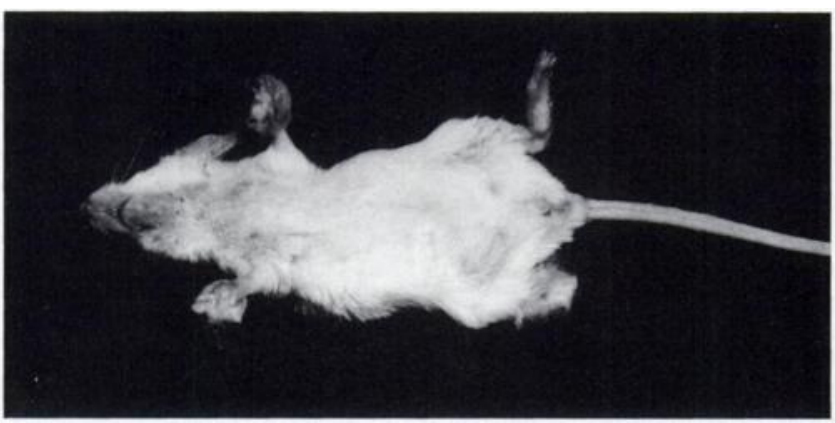

B

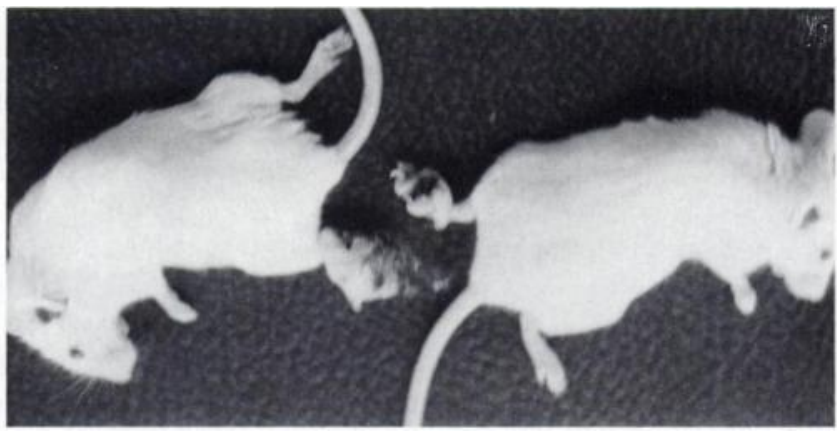

C

FIGURE 2. A, BALB/c mice 15-weeks postinfection with Leishmania amazonensis (left) isolated from a patient with visceral leishmaniasis, showing a small footpad lesion and (right) from a patient with mucosal leishmaniasis, showing a larger footpad lesion and metastasis to the tail (arrow). B, a BALB/c mouse 23-weeks postinfection with $L$ amazonensis isolated from a patient with mucosal leishmaniasis. The infection has disseminated to all four footpads, with lost of the rear left one. C, BALB/c mice 43-weeks postinfection with $L$. amazonensis isolated from a patient with visceral leishmaniasis. The lesions are limited to the infected footpads and no metastasis was detected at this time.

The splenic index (spleen weight/body weight $\times 100$ ) at three, eight, and 15-weeks postinfection differed between the cutaneous/mucosal groups and visceral groups. In the cutaneous/mucosal groups, the splenic index increased during the course of the disease and in the visceral group, it decreased over time. At 15-weeks postinfection, the difference in the splenic index between the cutaneous/mucosal groups and the visceral group was statistically significant $(P<$ 0.005) (Figure 4).

Parasite dissemination. Table 1 shows data on Leish-

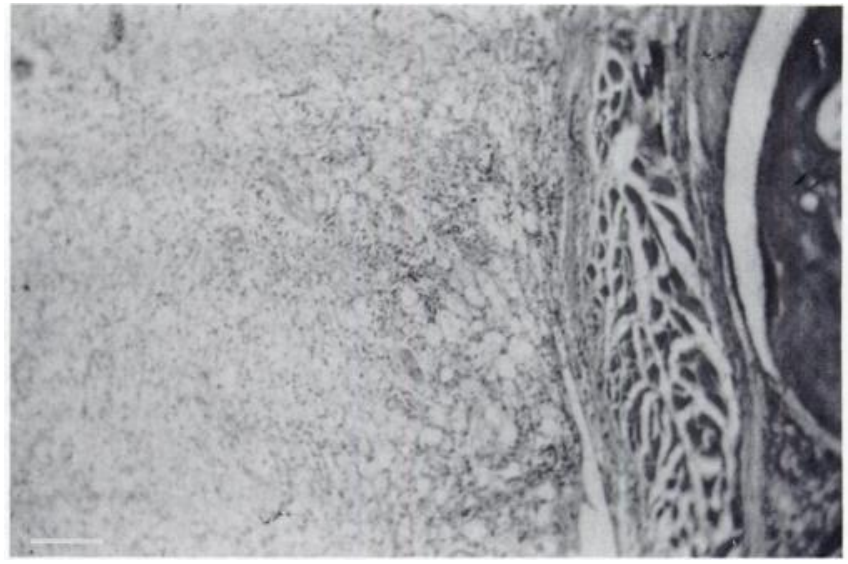

A

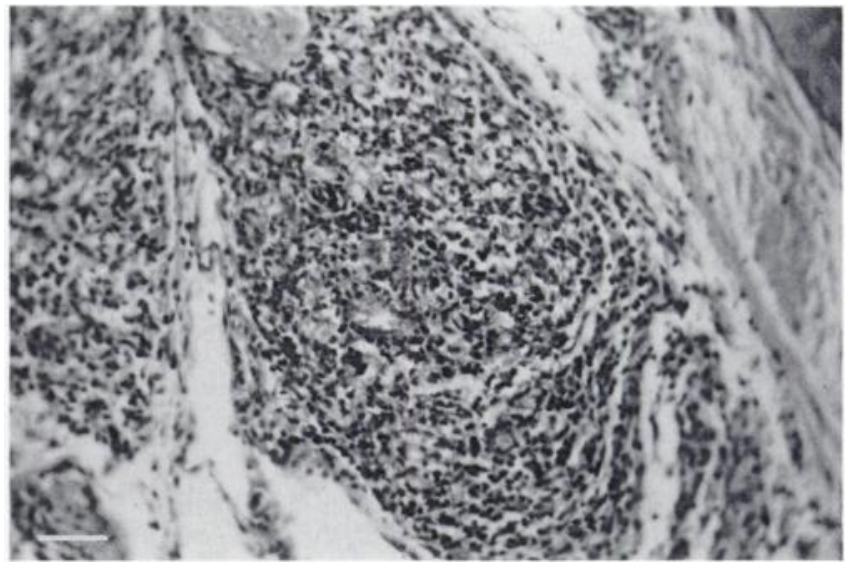

B

Figure 3. A, histopathologic analysis showing a necrotic and ulcerated footpad lesion from a BALB/c mouse 15-weeks postinfection with Leishmania amazonensis isolated from a patient with mucosal leishmaniasis. The lesion is full of macrophages with amastigotes inside (hematoxylin and eosin stained, bar $=50 \mu \mathrm{m}$ ). B, histopathologic analysis of a footpad lesion from a BALB/c mouse 15weeks postinfection with $L$ amazonensis isolated from a patient with visceral leishmaniasis. The lesion shows a mononuclear infiltrate, without necrosis, and the presence of granuloma formation (hematoxylin and eosin stained, $\mathrm{bar}=78 \mu \mathrm{m}$ ).

mania cultures in NNN medium obtained from whole spleens or lymph node cells of $B A L B / c$ mice after three, eight, and 15 weeks of infection with either cutaneous/mucosal or visceral strains of $L$. amazonensis. At three weeks postinfection, seven (46\%) of 15 spleen cell cultures and 11 (73\%) of 15 lymph node cell cultures were positive in the cutaneous/mucosal groups, while none of the spleen cell cultures were positive in the visceral group, despite positivity in $70 \%$ of the lymph node cultures. Similar findings in both groups were observed at eight-weeks postinfection. At 15weeks post infection, all cultures were positive, except for two $(22 \%)$ of nine cultures of spleen cells in the visceral group. To evaluate the possibility that a large number of spleen cells could interfere with promastigote proliferation, spleen cells were adjusted to a concentration of $1 \times 10^{7}$ cells $/ \mathrm{ml}$ before being seeded for culture. There was no difference in the number of positive cultures when spleen cells 


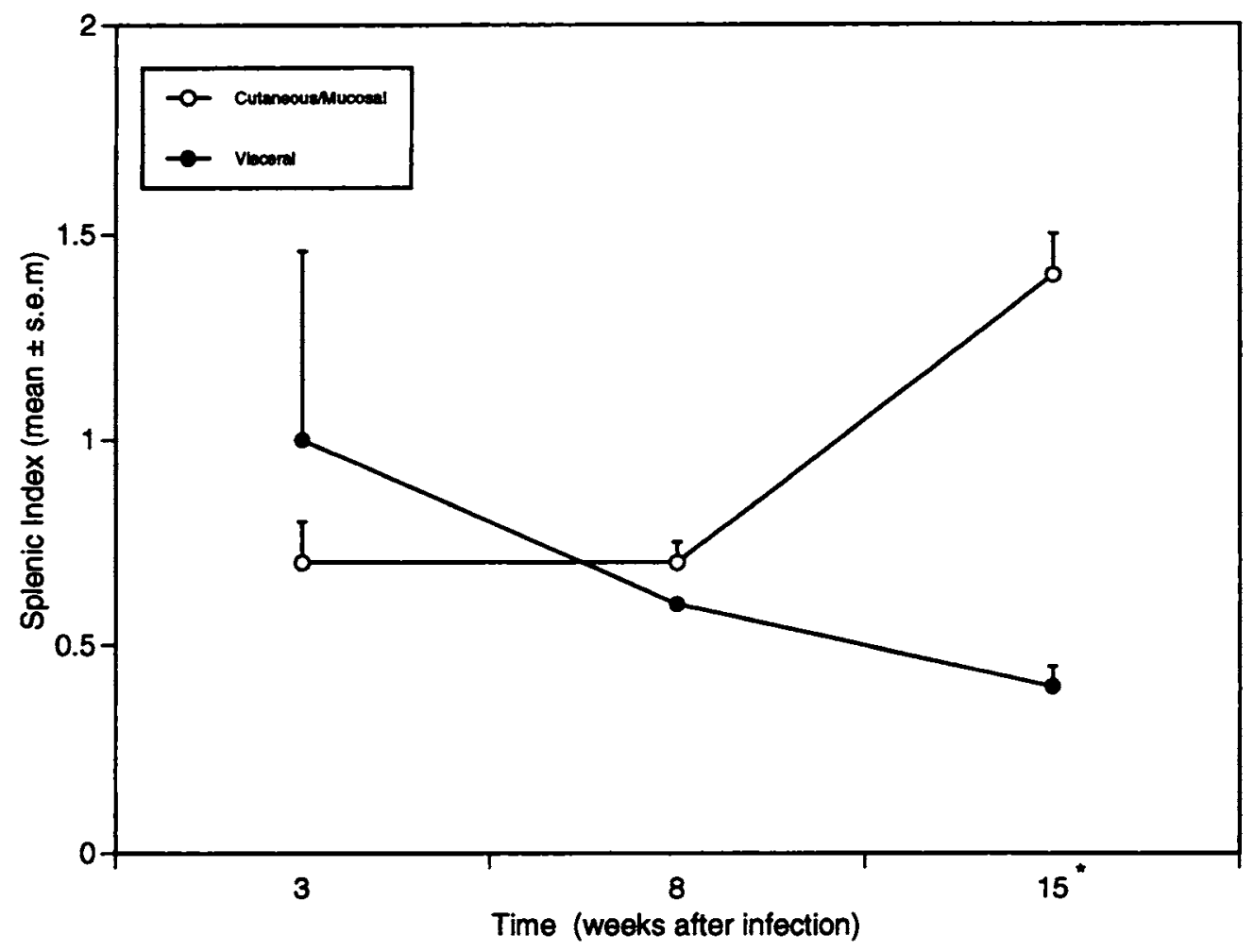

FIGURE 4. Evolution of the splenic index (spleen weight/body weight $\times 100$ ) of BALB/c mice infected with $5 \times 10^{6}$ promastigotes of Leishmania amazonensis isolated from patients with either cutaneous/mucosal or visceral leishmaniasis. Points represent the mean \pm SEM index of five spleens at each timepoint for each group, except for the visceral group at eight-weeks postinfection $(n=4)$. ${ }^{*}<0.005$, by the Mann-Whitney test.

were adjusted to a concentration of $1 \times 10^{7}$ cells $/ \mathrm{ml}$, as compared with the whole macerated spleen.

Antibody response. Serum levels of total anti-Leishmania IgG antibody increased in both groups with the progression of the infection. After three and seven weeks, antibody titers were similar in the cutaneous/mucosal and visceral groups. At 10-weeks postinfection, antibody titers were significantly higher in the cutaneous/mucosal groups than in the visceral group $(2.4 \pm 0.30$ versus $1.65 \pm 0.45$ [mean \pm SEM], Figure 5). Serum levels of anti-Leishmania IgG1 antibodies in-

TABLE 1

Dissemination of the five Leishmania amazonensis strains in BALB/ c mice to spleen and lymph node after three, eight, and 15 weeks after infection

\begin{tabular}{lllll}
\hline & \multicolumn{4}{c}{ No. of positive cultures* } \\
\cline { 2 - 5 } L amazonensis & & \multicolumn{3}{c}{ Weeks after infection } \\
\cline { 2 - 5 } isolates & Organ & 3 & 8 & 15 \\
\hline Visceral-1 & Spleen & 0 & 0 & 4 \\
& Lymph node & 5 & 4 & 5 \\
Visceral-2 & Spleen & 0 & 1 & $3 \dagger$ \\
& Lymph node & 2 & 4 & $4 \dagger$ \\
Mucosal-1 & Spleen & 3 & 5 & 5 \\
& Lymph node & 3 & 2 & 5 \\
Mucosal-2 & Spleen & 2 & 3 & 5 \\
& Lymph node & 3 & 5 & 5 \\
Cutaneous & Spleen & 2 & 5 & 5 \\
& Lymph node & 5 & 5 & 5 \\
\hline
\end{tabular}

Of five cultures. creased between three- and 10-weeks postinfection in both groups, although they were higher in the cutaneous/mucosal groups. Serum levels of anti-Leishmania IgG2a also increased between three and seven weeks in both groups. Between seven- and 10-weeks postinfection, serum levels of specific IgG2a antibodies increased in the visceral group and remained the same in the cutaneous and mucosal groups.

Since the absolute serum levels of total IgG anti-Leishmania antibodies from the cutaneous/mucosal groups of mice were different from the visceral groups of mice, we calculated the IgG1 and IgG2a indices (anti-Leishmania IgG1 or IgG2a OD/total anti-Leishmania IgG OD) to compare the contribution of these specific IgG subclasses to this difference. The IgG1 index increased in both groups from between three- and 10-weeks postinfection, and at 10-weeks postinfection they had similar IgG1 index values. The IgG2a index decreased throughout the course of the disease in the cutaneous/mucosal groups, but increased in the visceral group. (Figure 6). The IgGl index increase was associated with the evolution of the footpad lesion in both groups, regardless of the relative control of the disease in the visceral group. The IgG2a index decreased dramatically in the cutaneous/mucosal groups but remained high in the visceral group, without decreasing, even at 10-weeks postinfection when lesion size started to increase (Figure 6). At 10 weeks, the visceral $\operatorname{lgG} 2 \mathrm{a}$ index and lesion size were similar to the cutaneous/mucosal groups lesions and IgG2a index at threeweeks postinfection. 


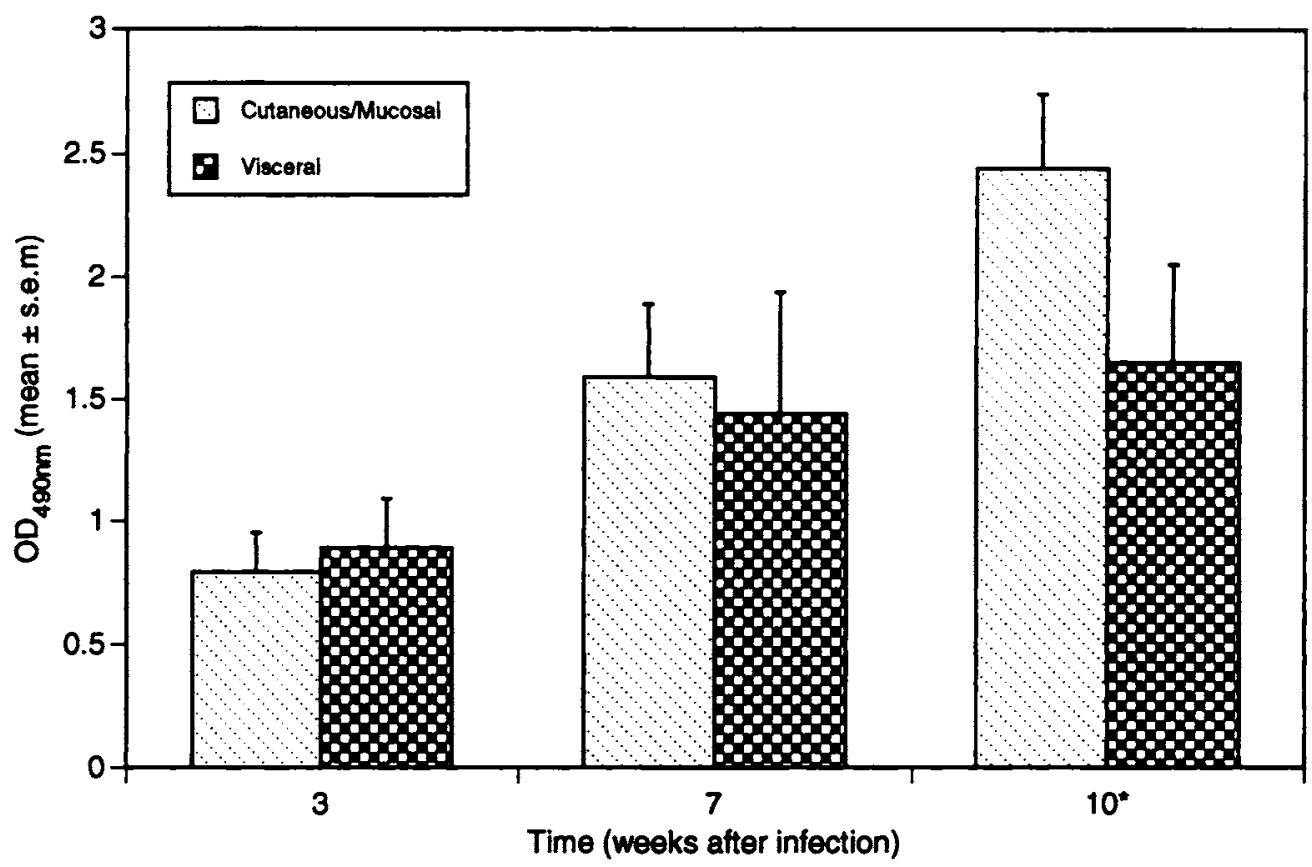

Figure 5. Evolution of serum levels of anti-Leishmania IgG antibody of BALB/c mice infected with $5 \times 10^{6}$ promastigotes of Leishmania amazonensis isolated from patients with cutaneous/mucosal and visceral leishmaniasis. Bars represent the mean \pm SEM optical density at 490 $\mathrm{nm}\left(\mathrm{OD}_{490}\right)$ of sera from each group, as determined by an enzyme-linked immunosorbent assay. " $P<0.05$, by the Mann-Whitney test.

\section{DISCUSSION}

In the present study $L$ amazonensis isolates produced different patterns of disease in BALB/c mice. The disease caused by $L$ amazonensis isolated from patients with visceral leishmaniasis was characterized by small lesions with a large number of lymphocytes, granuloma formation, and few infected macrophages. There were no metastases even after 48 weeks of observation. These lesions contrasted with those caused by isolates obtained from patients with either cutaneous or mucosal disease. Animals infected with these parasites developed severe destructive lesions and progressed to death after 15 weeks. Histologically, the lesions displayed a monomorphic appearance with heavily infected macrophages. This pattern of severe disease corresponds to that which has been shown in BALB/c mice infected with $L$. amazonensis or $L$. major ${ }^{7,10-13}$ On the other hand, resistant mouse strains (C57B1/6 or vaccinated BALB/c mice have a controlled infection. ${ }^{14,15}$ Histologically, lesions from resistant animals show a mononuclear infiltration, few infected macrophages, granuloma formation, and fibrinoid necrosis that are not seen in unvaccinated, susceptible animals. ${ }^{5.11}$ These histologic findings correlate with a good prognosis of the infection in these animals, as well as in natural infection in humans. In the present study, the course of the disease and the histologic data on the lesions suggest good prognosis in the BALB/c mice infected with the visceral isolates of $L$. amazonensis.

Spleen weight also differed between animals infected with cutaneous/mucosal or visceral isolates. Animals infected with visceral strains initially had an increase in the spleen weight but showed a gradual decrease with the evolution of the disease, whereas animals infected with cutaneous isolates exhibited a progressive increase in spleen weight. Reduction of spleen size in visceral leishmaniasis patients is associated with cure of the disease. ${ }^{16}$

Parasite dissemination to the popliteal lymph nodes occurred at three-weeks postinfection in both groups infected with cutaneous/mucosal or visceral isolates. However, the dissemination to the spleen occurred earlier (three weeks) in BALB/c mice infected with cutaneous/mucosal isolates than in mice infected with visceral isolates (eight weeks). In a previous study, parasites were detected in the lymph nodes and spleens of BALB/c mice two weeks after infection, whereas C57BV/6 mice parasites were detected only after seven weeks of infection. ${ }^{17}$ Other studies have demonstrated that early dissemination of different species of Leishmania to the spleen and lymph nodes correlates with severity of the disease. ${ }^{17}$ Thus, the pattern of dissemination of parasites to these lymphoid organs is related to resistance to the infection, as demonstrated in the present study.

Collectively, the absence of spleen enlargement, lack of metastatic lesions, and the histopathologic findings of the lesion are indicative of partial resistance and control of the disease in BALB/c mice infected with visceral isolates of $L$. amazonensis. Kahl and others, studying the pattern of disease in hamsters infected with two isolates of $L$ braziliensis obtained from patients with mucocutaneous and cutaneous leishmaniasis, also described different course of disease in these animals. ${ }^{18,19}$

The control of leishmanial infection in susceptible animals has been obtained only through the use of attenuated parasites or by manipulation of the immune system of these animals with such approaches as sublethal irradiation, depletion of $\mathrm{L}^{3} 4^{+}$cells, or vaccination. ${ }^{14,15,20,21}$ The parasites used in the present study were not intentionally attenuated. They were recently isolated and were used for infection before the third in vitro passage. 

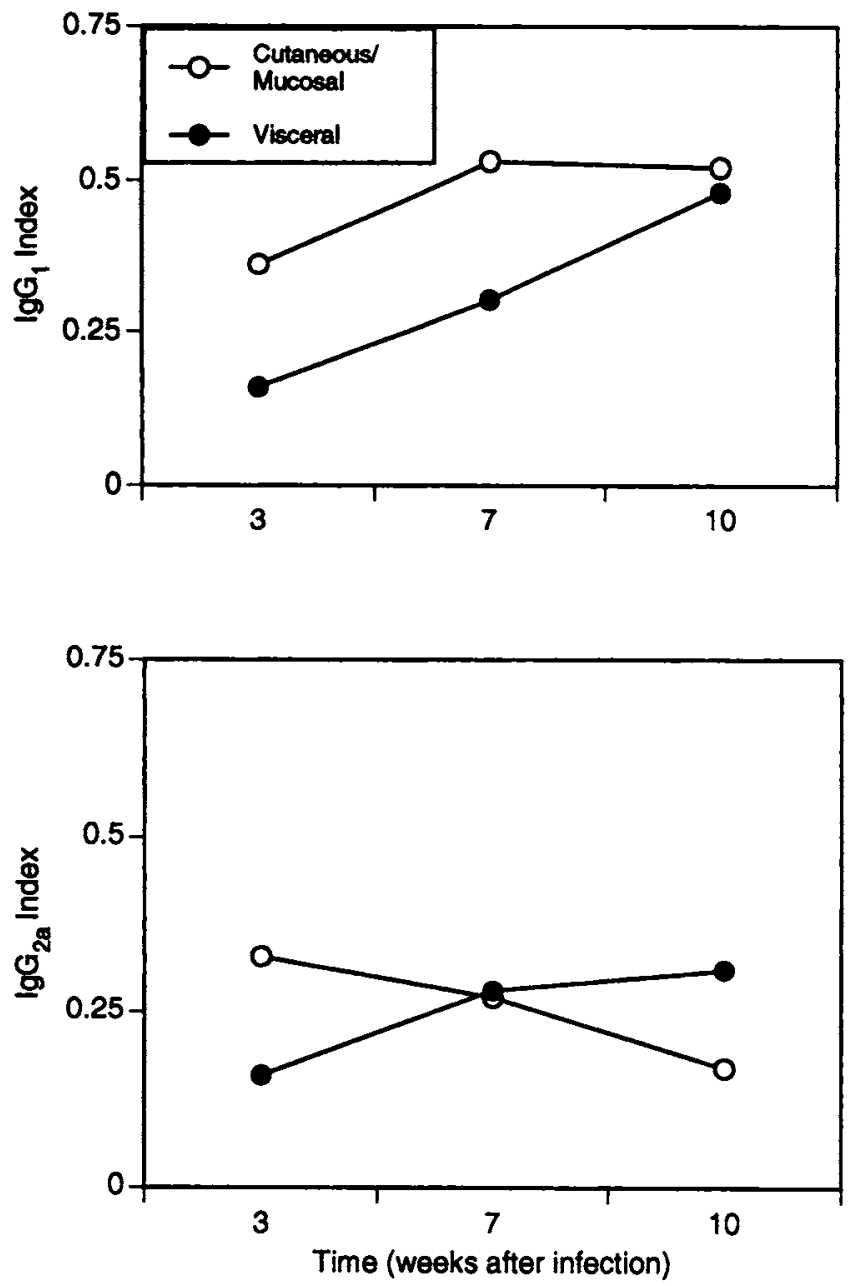

FIGURE 6 Evolution of specific IgG1 and IgG2 indices (antiLeishmania IgG1 or IgG2a optical density [OD]/total anti-

Leishmania IgG OD) of BALB/c mice infected with $5 \times 10^{6}$ promastigotes of $L$ amazonensis isolated from patients with cutaneous/ mucosal and visceral leishmaniasis. Points represent the mean \pm SEM IgG1 or IgG2a indices of sera from each group.

A previous study using a visceral isolate of this species in $\mathrm{BALB} / \mathrm{c}$ mice showed a disease course similar to the one observed with cutaneous and mucosal isolates. ${ }^{2}$ Although we had the same pattern of disease in independent experiments with two different visceral isolates in this study, we cannot generalize these findings to all visceral isolates of $L$. amazonensis.

The possibility that there were two different parasite species ( $L$ amazonensis and $L$. chagasi) in our isolates from patients with visceral leishmaniasis is very unlikely for at least three reasons. First, our isolates were typed twice, before and after the mouse infections, and always exhibited the same pattern of reactivity with a large monoclonal antibody panel. Second, in the case of a mixed infection, $L$ amazonensis, a faster-growing strain than $L$ chagasi, would have superseded the other, and in this case an accelerated course of disease would have prevailed. Third, the isolate visceral2 was reisolated from $B A L B / c$ during the present study, was used to reinfect $B A L B / c$ mice, and caused a disease with a pattern similar to the first infection. Additionally, a similar laboratory contamination in two different isolates obtained and grown at different times is very unlikely.

Anti-Leishmania antibody levels were lower in animals infected with the visceral isolates than in those infected with cutaneous/mucosal isolates. Higher antibody levels are observed in susceptible animals (e.g., BALB/c mice) as compared with those resistant to $L$ mexicana or $L$ major infections. ${ }^{22}$ Lower anti- $L$ amazonensis IgG antibody levels in BALB/c mice infected with visceral isolates can be taken as further evidence of resistance against these isolates.

Expansion of Thl cells, which produce interleukin-2 and interferon-gamma, are associated with the production of IgG2a antibody, whereas Th2 cells activate B cells for the production of IgG1 and IgE antibodies. ${ }^{23}$ In murine leishmaniasis, Th1 cells are instrumental for resistance against the infection. ${ }^{23.24}$ Specific IgG1 and IgG2a levels were determined in this study was done in an attempt to indirectly evaluate the type of cellular immune response predominant in BALB/c mice infected by different strains. The IgG2a, as a percentage of total IgG, increased in animals infected with the visceral isolates and decreased in those infected with the cutaneous/mucosal isolates of $L$ amazonensis. Our findings of increasing specific IgG2a production by animals infected with visceral isolates suggest a predominance of Th1 cells and correlate with partial protection against the disease. Morris and others ${ }^{25}$ have shown that BALB/c mice infected with $L$ major had anti- $L$ major IgGl levels that correlated with disease evolution. However, no correlation with specific IgG2a levels and lesion development was shown among several mouse strains resistant or susceptible to $L$. major infection. Our data show similar results concerning IgGl levels and disease evolution in both groups, but in our present work, the IgG2a index decreased in the cutaneous/mucosal groups and inversely correlated with the disease evolution and increased in the visceral group, in which the lesions were partially controlled. Recently, Afonso and Scott ${ }^{26}$ have shown that the susceptibility of C57B1/10 mice infected with $L$. amazonensis is due to the absence of Thl cell response, rather than to the presence of a Th2 cell response. Our results showed that resistance of BALB/c mice infected with visceral isolates of $L$ amazonensis could be also correlated with an expression of a Th1 cell response in these animals, as the specific IgG2a levels and lesion evolution suggest.

The results in the present paper show that isolates typed as $L$. amazonensis promote a different course of infection in inbred $\mathrm{BALB} / \mathrm{c}$ mice. These strains were isolated from patients with distinct clinical presentations of disease. In the human host, however, the differences in the evolution of the disease could be due to host genetic dissimilarities. The confirmation of a different course of disease using uncloned isolates in a genetically homogeneous host, such as inbred BALB/c mice, suggests that a phenotypic difference does exist between these parasites and casts doubt on the biological meaning of currently used methods for parasite typing. It is possible that subtle differences among various parasite isolates, not related with the characteristics or molecules used in current taxonomy, are important in determining the course of leishmaniasis.

Acknowledgments: We are grateful to Lucia Mara McAllister-Viana and Elbe Souza for secretarial assistance, Vanilson Souza for animal 
care, and Christian Bogdan and Warren Johnson for manuscript review.

Financial support: This work was supported by NIH grant AI-30639 and the UNDP/World Bank/WHO Special Program for Research and Training in Tropical Diseases (TDR).

Authors' address: Roque P. Almeida, Manoel Barral-Netto, Amelia M. R. de Jesus, Edgar M. Carvalho, and Aldina Barral, Laboratorio de Imunologia, Hospital Universitario Professor Edgard Santos, $3^{\circ}$ andar, Rua Joao das Botas s/n Canela, 40110-160 Salvador, Bahia. Brazil. Luis A. R. de Freitas, Centro de Pesquisa Goncalo MonizFIOCRUZ, Bahia, Brazil.

Reprint requests: Roque P. Almeida, Laboratorio de Imunologia, Hospital Universitario Professor Edgard Santos, $3^{\circ}$ andar, Rua Joao das Botas s/n Canela, 40110-160 Salvador, Bahia, Brazil.

\section{REFERENCES}

1. Barral A, Pedral-Sampaio D, Grimaidi G Jr, Momem H, McMahon-Pratt D, Ribeiro de Jesus A, Almeida RP, Badaro R, Barral-Netto M, Carvalho EM, Johnson WD Jr, 1991. Leishmania amazonensis is implicated in the whole spectrum of human clinical leishmaniasis. Am J Trop Med Hyg 44: 536546.

2. Barral A, Badaro R, Barral-Neto M, Grimaidi G Jr, Momem H, Carvalho EM, 1986. Isolation of Leishmania mexicana amazonensis from the bone marrow in a case of American visceral leishmaniasis. Am J Trop Med Hyg 35: 732-734.

3. Sampaio RN, Marsden PD, Llanos-Cuentas EA, Cuba CC, Grimaldi $G$ Jr, 1985. Leishmania mexicana amazonensis isolated from a patient with fatal mucosal leishmaniasis. Rev Soc Bras Med Trop 18: 273-274.

4. Magill N, Grogl M, Gasser RA, Wellington S, Oster CN, 1993. Viscerotropic leishmaniasis caused by Leishmania tropica in soldiers returning from Operation Desert Storm. $N$ Eng J Med 328: 1383-1387.

5. Andrade ZA, Reed SG, Roters SB, Sadigursky M, 1984. Immunopathology of experimental cutaneous leishmaniasis. Am J Pathol 114: 137-148.

6. Shaw BA, Grayson JB, Petersen EA, 1987. Experimental murine infection with the diffuse cutaneous leishmaniasis strain, Isabel. Ann Trop Med Parasitol 81: 9-14.

7. Barral-Netto M, de Freitas LAR, Andrade ZA, 1987. Histopathologic changes induced by vaccination in experimental cutaneous leishmaniasis of BALB/c Mice. Am J Pathol 127: 271-277.

8. Grimaldi G Jr, David J, McMahon-Pratt D, 1987. Identification of new world leishmaniasis species characterized by serodema analysis using monoclonal antibodies. Am J Trop Med Hyg 36: 270-287.

9. Badaro R, Reed SG, Barral A, Orge G, Jones TC, 1986. Evaluation of the micro enzyme-linked immunoabsobent assay (ELISA) for antibodies in American visceral leishmaniasis antigen selection for detection of infection-specific responses. Am J Trop Med Hyg 35: 72-78.

10. Perez H, Labrador F, Torrealba JW, 1979. Variations in the response of five strains of mice to Leishmania mexicana. Int $J$ Parasitol 9: 27-31.

11. Nasseri M, Modabber FZ, 1979. Generalized infection and lack of delayed hypersensitivity in BALB/c mice infected with Leishmania tropica major. Infect Immun 26: 611-614.
12. Leclerc C. Modabber F, Deriaud E, Chedid L, 1981. Systemic infection of Leishmania tropica (major) in various strains of mice: (a re-evaluation of the concept of dermatotropism). Trans R Soc Trop Med Hyg 75: 851-854.

13. Liew FY, Howard JG, Hale C, 1984. Prophylactic immunization against experimental leishmaniasis. III. Protection against fatal Leishmania tropica infection induced by irradiated promastigotes involves Lyt $1+2-T$ cells that do not mediate cutaneous DTH. J Immunol 132: 456-461.

14. Scott $P$, Pearce $E$, Natovitz $P$, Sher $A, 1987$. Vaccination against cutaneous leishmaniasis in a murine model. I. Induction of protective immunity with a soluble promastigote extract. $J$ Immunol 139: 221-227.

15. Scott $P$, Pearce E, Natovitz $P$, Sher A, 1987. Vaccination against cutaneous leishmaniasis in a murine model. II. Immunologic properties of protective and non-protective subfractions of a soluble promastigote extract. $J$ /mmunol 139: 3118-3125.

16. Badaro R, Falcoff E, Badaro FS, Carvalho EM, Pedral-Sampaio D, Barral A, Carvalho JS, Barral-Netto M, Brandeley M, Silva L, Bina JC, Teixeira R, Falcoff F, Rocha $H$, Ho J, Johnson WD Jr, 1990. Treatment of visceral leishmaniasis with pentavalent antimony and interferon gamma. $N$ Engl $J$ Med 322: $16-21$.

17. Scott P, Farrel JP, 1982. Experimental cutaneous leishmaniasis: disseminated leishmaniasis in genetically susceptible and resistant mice. Am J Trop Med Hyg 31: 230-238.

18. Kahl LP, Byram JE, David JR, 1990. Leishmania (Viannia) braziliensis isolated from cutaneous and mucosal lesions of patients residing in Tres Bracos, Bahia, Brazil differ in virulence for the golden hamster. Trans R Soc Trop Med Hyg 84: 783784.

19. Kahl LP, Byram JE, David JR, Comerford SA, Von Lichtenberg F, 1991. Leishmania (Viannia) braziliensis comparative pathology of golden hamsters infected with isolates from cutaneous and mucosal lesions of patients residing in Tres Bracos, Bahia, Brazil. Am J Trop Med Hyg 44: 218-232.

20. Titus RG, Ceredig R, Cerrottini JC, Louis JA, 1985. Therapeutic effect of anti-L3T4 monoclonal GK 1.5 on cutaneous leishmaniasis in genetically susceptible BALB/c mice. $J$ Immunol 135: 2108-2114.

21. Scott $P, 1991$. IFN- $y$ modulates the early development of Th1 and Th2 responses in a murine model of cutaneous leishmaniasis. J Immunol 147: 3149-3155.

22. Perez H, Arrendondo B. Gonzalez M, 1978. Comparative study of American cutaneous leishmaniasis and diffuse cutaneous leishmaniasis in two strains of inbred mice. Infect Immun 22 301-307.

23. Mosmann TR, Cherwinski H, Bond MW, Giedlin MA, Coffman RL, 1986. Two types of marine helper T cell clone. I. Definition according to profiles of lymphokine activities and secreted proteins. $J$ Immunol 136: 2348-2357.

24. Scott P, Natovitz P, Coffman RL, Pearce E, Sher A, 1988. Immunoregulation of cutaneous leishmaniasis. $T$ cell lines that transfer protective immunity or exacerbation belong to different $T$ helper subsets and respond to distinct parasite antigens. J Exp Med 168: 1675-1684.

25. Morris L, Troutt AB, McLeod KS, Kelso A, Handman E, Aebischer $T, 1993$. Interleukin-4 but not gamma inteferon production correlates with severity of murine cutaneous leishmaniasis. Infect Immun 61: 3459-3465.

26. Afonso LC, Scott $P, 1993$. Immune response associated with susceptibility of C57BL/10 mice to Leishmania amazonensis. Infect Immun 61: 2952-2959. 